\title{
CARACTERÍSTICAS DO APOIO INSTITUCIONAL OFERTADO ÀS EQUIPES DE ATENÇÃO BÁSICA NO BRASIL
}

\author{
CHARACTERISTICS OF THE INSTITUTIONAL SUPPORT \\ OFFERED TO BASIC CARE TEAMS IN BRAZIL
}

\author{
CARACTERÍSTICAS DEL APOYO INSTITUCIONAL OFRECIDO A \\ LOS EQUIPOS DE ATENCIÓN BÁSICA EN BRASIL
}

Lygia Maria de Figueiredo Melo

Claudia Santos Martiniano ${ }^{2}$

Ardigleusa Alves Coelho ${ }^{3}$

Marize Barros de Souza ${ }^{4}$

Themis Xavier de Albuquerque Pinheiro ${ }^{5}$

Paulo de Medeiros Rocha ${ }^{6}$

Resumo Objetivou-se nesta pesquisa quantitativa descritiva analisar o apoio institucional nas equipes que aderiram ao Programa de Melhoria do Acesso e da Qualidade da Atenção Básica. A coleta de dados foi realizada no período de fevereiro a outubro de 2014, a partir do banco de dados da avaliação externa do programa. A amostra compreendeu 2.941 respondentes do módulo II e os 22 gestores que responderam ao módulo IV (on line). As variáveis foram analisadas por meio da estatística descritiva, com uso do software IBM SPSS e os resultados organizados e agrupados em três dimensões: características do apoio institucional; processo de trabalho do apoiador institucional e apoio da gestão na administração e planejamento dos processos de trabalho. Observou-se que o apoio é uma realidade na atenção básica, porém identificou-se, nas ações apoiadas, um traço normalizador e burocrático. $\mathrm{O}$ apoiador institucional foi avaliado positivamente, embora se encontre sobrecarregado pelo número excessivo de equipes sob sua responsabilidade, evidenciando-se a necessidade de um dimensionamento que leve em consideração o modo de operar a função apoio. Em virtude das características do instrumento de coleta, não foi possível identificar qual a concepção de apoio dos entrevistados, constituindo-se um limite do estudo.

Palavras-chave gestão em saúde; apoio institucional; atenção básica.

\begin{abstract}
The purpose of this descriptive quantitative study was to analyze institutional support among the teams that joined the Program for the Improvement of Access to and Quality of Primary Care. Data were collected from February to October 2014 from the program's external evaluation database. The sample comprised 2941 respondents from module II, and the 22 managers who replied to module IV (on line). The variables were analyzed through descriptive statistics, using the IBM SPSS software, and the results were organized and grouped into three dimensions: Characteristics of the institutional support; the work of the institutional supporter, and management support in work process management and planning. It was noted that there is support in basic care; however, a normalizing and bureaucratic trait was identified in the actions supported. The institutional supporter was evaluated positively, although being overwhelmed by the excessive number of teams under their responsibility, evidencing the need for sizing that takes into account the way the support function operates. Due to the collection instrument's characteristics, it was not possible to identify the interviewees' concept of support, this being a limitation of the study.
\end{abstract}

Keywords health management; institutional support; primary care. 


\section{Introdução}

Este artigo apresenta e discute o apoio institucional nos serviços de atenção básica das capitais brasileiras a partir dos resultados da Avaliação Externa (Ciclo I) do Programa de Melhoria da Qualidade e do Acesso da Atenção Básica (PMAQ-AB), criado pelo Ministério da Saúde (MS), em julho de 2011 (Brasil, 2011) e tem como objetivo identificar as características do apoio institucional e do trabalho do apoiador junto às equipes de atenção básica.

No contexto organizacional da saúde, pôr em análise as instituições e os processos de trabalho têm se constituído, nos últimos anos, um desafio e, ao mesmo tempo, uma diretriz assumida pelo MS, pelos governos estaduais e municipais e pelos trabalhadores. Esse movimento implica assumir um compromisso com a complexidade intrínseca aos processos de mudança que se voltam para alterar o modo de gestão das instituições de saúde, numa perspectiva mais democrática e um Sistema Único de Saúde (SUS) mais resolutivo e de qualidade. Desse modo, a análise dos dados aqui apresentada articula-se ao que afirma Gastão Wagner, quando propôs, nos anos 2000, o apoio institucional Paideia apostando no campo da possibilidade de mudança cotidiana, a partir da instauração de processos instituintes e sujeitos autônomos, o que significa pensar o apoio como método/dispositivo, o qual coloca em análise o autoritarismo produzido nas práticas de saúde, constituindo-se em uma ferramenta valiosa para a construção da democracia institucional e autonomia dos sujeitos, ou seja, possibilidade de construir outro paradigma de gestão, produzir outras formas de gestão do trabalho e ainda alterar a gestão das organizações e instituições de saúde (Campos, 2000; Guedes; Roza; Barros, 2012; Oliveira, 2012; Campos; Cunha; Figueiredo, 2013; Campos, 2014).

Adotando como princípio a cogestão, o apoio institucional possibilita desenvolver nas pessoas, por meio de um trabalho sistemático, maior capacidade de reflexão, julgamento e ação, sobre o mundo em que vivem e trabalham, quer sejam interferindo nos fatores externos, como as organizações, leis, normas e tradições, ou internos ao sujeito, nos quais está inserida a formação da sua personalidade e do seu caráter (Campos, 2008). Nessa perspectiva, a gestão sempre será uma tarefa coletiva; uma ação exercida entre sujeitos com diferentes graus de saber e poder.

Na visão de Pereira Júnior e Campos (2014) o movimento de institucionalização do apoio disparado a partir da incorporação do método Paideia ao discurso oficial da gestão federal do SUS ocorre, inicialmente, por meio de dois movimentos do MS: Política Nacional de Humanização (PNH) (Brasil, 2003) e publicações do Departamento de Apoio à Descentralização (DAD), entre elas, o Apoio integrado à gestão descentralizada do SUS (Brasil, 2004). Soma-se ainda a existência de movimentos induzidos, principalmente, nos últimos anos, pelas várias experimentações de modalidades do apoio (Oliveira, 2010; Guedes, Roza e Barros, 2012; Pavan e Trajano, 2014). 
Corroborando esse movimento, o PMAQ-AB inclui o apoio institucional como eixo estratégico transversal de desenvolvimento, objetivando a promoção de movimentos de mudança da gestão, do cuidado, e da gestão do cuidado que impactarão na melhoria do acesso e da qualidade das ações ofertadas à população. (Brasil, 2015).

Desse modo, institucionalmente, o apoio tem sido reconhecido na perspectiva de Campos (2014) como ferramenta de ampliação da democracia institucional e autonomia dos sujeitos e, portanto, uma via para alterar os modelos de gestão verticalizados e autoritários, ainda tão presentes no SUS.

No exercício de sua função, o apoiador desenvolve ações que são fundamentais no rompimento da alienação cotidiana do trabalho mediante a ativação de processos de mudança, assumindo o trabalho de coletivos organizados, como objeto de sua intervenção.

No momento em que as reformas no campo da gestão e do cuidado se colocam como fundamentais para o fortalecimento da atenção básica em todos os sistemas de saúde e particularmente para o SUS, acredita-se ser relevante o esforço empreendido com essa pesquisa no sentido de contribuir para a reflexão sobre como tem se dado, no contexto do SUS, a institucionalização do apoio e a sua capacidade de ampliar a democracia.

\section{Método}

A avaliação externa do PMAQ-AB consistiu de uma pesquisa de natureza avaliativa realizada no período de maio a agosto de 2012 e se caracterizou por um estudo transversal e multicêntrico. Participaram da pesquisa de avaliação externa 3.977 municípios o que correspondeu a 71,4\% dos municípios brasileiros e 13.920 unidades básicas de saúde. Foram entrevistados 17.202 profissionais e 65.391 usuários. A adesão do município ao PMAQ-AB foi o único critério de inclusão adotado.

Entre os municípios participantes da avaliação externa do PMAQ-AB, optou-se por um recorte intencional para a análise da oferta do apoio institucional às equipes pelas gestões de atenção básica das capitais brasileiras, visto que estudos têm demonstrado que, nos municípios com população acima de $100 \mathrm{mil}$ habitantes, além dos problemas relacionados às condições desiguais de acesso aos serviços e à qualidade da assistência prestada à população, há outros desafios, como problemas de ordem econômico-social comuns aos grandes centros urbanos; a fraca integração dos serviços de atenção básica com outros níveis de atenção e, ainda, uma implantação incipiente e pontual da Estratégia Saúde da Família (Senna, Costa e Silva, 2010; Giovanella, Escorel e Mendonça, 2009).

Do universo das 27 capitais brasileiras, quatro não aderiram ao PMAQ-AB (Macapá, São Luís, Teresina e Maceió). Em uma das capitais incluídas na pesquisa (Boa Vista), o gestor da atenção básica não respondeu ao Módulo IV, e foi 
excluída do estudo. Desse modo, a amostra se constituiu de 22 formulários respondidos pelas gestões das capitais.

Para a coleta de dados, foram utilizados tablets com envio direto das informações on line para o Departamento de Atenção Básica do MS, tendo sido realizado mediante a aplicação dos instrumentos de coleta, a saber: módulo II - processo de trabalho das equipes e módulo IV (on line) respondido pelo gestor da atenção básica e pelo profissional responsável da equipe da $\mathrm{AB}$, entre outras questões, aquelas relacionadas ao apoio institucional da gestão para as equipes.

Além da validação externa, esses dados foram organizados em banco de dados e submetidos à análise de consistência interna pelas equipes de tecnologia da informação, estatística e epidemiologia e disponibilizados inicialmente para instituições universitárias que participaram do processo de avaliação externa.

Os dados extraídos do banco do PMAQ-AB utilizados nessa investigação foram sistematizados e apresentados na forma de gráficos e tabelas por meio do software IBM SPSS Statistics 20.

O projeto multicêntrico "Avaliação da Atenção Básica no Brasil: estudos multicêntricos integrados sobre acesso, qualidade e satisfação dos usuários" foi aprovado pelo Comitê de Ética em Pesquisa, da Universidade Federal do Rio Grande do Sul, sob o número 21.904 em 13 março de 2012, e está em consonância com a resolução n. 196/96, do Conselho Nacional de Saúde.

\section{Resultados}

Os entrevistados que responderam as questões dirigidas aos profissionais de saúde em todo o Brasil foram, preponderantemente, enfermeiros $(92,3 \%)$, enquanto que os médicos representaram apenas $5,8 \%$ dos entrevistados e os cirurgiões-dentistas, $1,9 \%$. Ao se analisar especificamente as equipes das capitais brasileiras, observou-se que a maioria dos respondentes foram enfermeiros(as) (82,3\%), seguidos dos médicos (14,6\%) e de cirurgiões-dentistas $(3,1 \%)$. Também, em relação aos respondentes, a maioria $(87,8 \%)$, no quadro nacional afirmou ser coordenador da equipe de atenção básica. Com um percentual um pouco mais baixo, os(as) enfermeiros(as) se destacam como respondentes/coordenadores nas equipes de atenção básica das capitais brasileiras $(80,3 \%)$.

Em relação ao tempo de atuação dos respondentes, verificou-se que, na média nacional, 56,5\% dos entrevistados afirmaram que variava de menos de um ano até dois. Nas capitais brasileiras, observou-se o mesmo comportamento $(46,3 \%)$.

Os resultados, apresentados abaixo, foram agrupados em três dimensões: características do apoio institucional, processo de trabalho do apoiador institucional e apoio da gestão na administração e planejamento dos processos de trabalho das equipes. 


\section{Características do apoio institucional}

A pesquisa confirmou que, para a grande maioria das equipes de atenção básica, há oferta de apoio institucional permanente. A média nacional encontrada foi de $77,9 \%$ e um pouco abaixo desse valor $(74,3 \%)$, nas capitais. Quando se questionou se a existência do apoio institucional ocorreu a partir da adesão do município ao PMAQ, verificou-se que apenas 6,3\% das gestões em todo o Brasil e 4,0\% das gestões municipais das capitais passaram a ofertar apoio institucional após a adesão ao programa.

Na Tabela 1, é possível visualizar que a quase totalidade das equipes das capitais foram apoiadas com percentuais que variavam de 50\% a $100 \%$. A exceção foi feita somente às equipes do município de Natal, em que apenas 35,50\% das equipes referiram receber apoio institucional permanente. Nesse universo, verificou-se a existência de capitais que, mesmo com um número reduzido de equipes com adesão ao PMAQ-AB, não receberam apoio no total de suas equipes, como é o caso de Cuiabá em que, apesar de apenas quatro equipes terem aderido ao PMA$\mathrm{Q}-\mathrm{AB}$, uma ficou sem receber apoio. Contudo, identificou-se um percentual de apoio em mais de 90\% em João Pessoa (93,2\%), Palmas (92,9\%) e Campo Grande $(100 \%)$, embora, nesta última capital, só tenha havido adesão de duas equipes.

\section{Tabela 1}

\begin{tabular}{|c|c|c|c|}
\hline \multicolumn{4}{|c|}{$\begin{array}{l}\text { Frequência e percentual das equipes que afirmaram receber apoio institucional permanente de uma equipe ou } \\
\text { pessoa da Secretaria Municipal de Saúde, capitais brasileiras, } 2012\end{array}$} \\
\hline Capitais Brasileiras & Número de equipes que aderiram ao $\mathrm{PMAQ-AB}$ & $\begin{array}{l}\text { Sim } \\
\text { (Fr) }\end{array}$ & $\underset{\%}{\operatorname{Sim}}$ \\
\hline Porto Velho & 57 & 32 & 56,1 \\
\hline Rio Branco & 11 & 6 & 54,50 \\
\hline Manaus & 34 & 19 & 55,90 \\
\hline Boa Vista & 14 & 7 & 50,00 \\
\hline Belém & 32 & 20 & 62,50 \\
\hline Palmas & 42 & 39 & 92,90 \\
\hline Fortaleza & 52 & 37 & 71,20 \\
\hline Natal & 31 & 11 & 35,50 \\
\hline João Pessoa & 88 & 82 & 93,20 \\
\hline Recife & 226 & 195 & 86,30 \\
\hline Aracaju & 45 & 24 & 53,30 \\
\hline Salvador & 55 & 39 & 70,90 \\
\hline Belo Horizonte & 534 & 401 & 75,10 \\
\hline Vitória & 75 & 44 & 58,70 \\
\hline Rio de Janeiro & 324 & 203 & 62,70 \\
\hline São Paulo & 790 & 628 & 79,50 \\
\hline Curitiba & 201 & 149 & 74,10 \\
\hline Florianópolis & 90 & 75 & 83,30 \\
\hline Porto Alegre & 54 & 34 & 63,00 \\
\hline Campo Grande & 2 & 2 & 100,00 \\
\hline Cuiabá & 4 & 3 & 75,00 \\
\hline Goiânia & 152 & 113 & 74,30 \\
\hline Brasília & 28 & 15 & 53,60 \\
\hline Total & 2941 & 2178 & 74,10 \\
\hline
\end{tabular}

Fonte: Elaborado pelos autores a partir do banco PMAQ (2012).

Nota: PMAQ-AB: Programa de Melhoria da Qualidade e do Acesso da Atenção Básica. 
Agrupando as capitais por região geográfica, percebeu-se que, proporcionalmente, é na região Centro-Oeste que se encontra o maior número de capitais com percentual de apoio acima de $70 \%$ e, na região Norte, a maior quantidade de capitais com percentuais de apoio abaixo desse valor.

No que se refere ao modo de contato do apoio institucional com as equipes, este tem ocorrido predominantemente de forma presencial, sendo $(80,8 \%)$ na média nacional e $72,8 \%$ nas capitais. Evidenciou-se pouco contato do apoiador com as equipes via internet (38,0\% nas capitais e $32,7 \%$ no Brasil). O telefone foi identificado como uma importante via de contato, tanto nas capitais $(60,4 \%)$ como em nível nacional $(66,5 \%)$.

Com relação às informações sobre quantidade de apoiadores institucionais, o questionamento foi dirigido tanto ao respondente das equipes quanto ao gestor.

De acordo com os respondentes do módulo II, na maioria das capitais, as equipes possuem até cinco apoiadores, predominando, no entanto, um apoiador por equipe $(33,2 \%)$, como observado no Gráfico 1 .

\section{Gráfico 1}

Distribuição percentual da quantidade de apoiadores para cada equipe segundo informação do respondente do módulo II. Capitais do Brasil, 2012

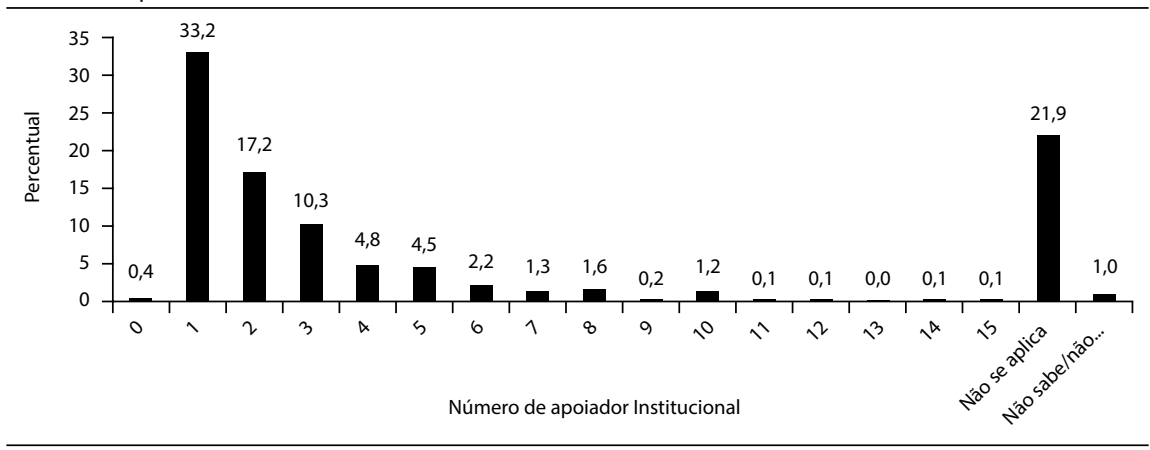

Fonte: Elaborado pelos autores, a partir do banco de dados do módulo II PMAQ (2012).

As informações dos gestores da atenção básica sobre a quantidade dos apoiadores apresentaram uma grande variação entre as capitais (Tabela 2). No que diz respeito à quantidade total de apoiadores institucionais permanentes para as equipes, observou-se uma considerável desproporção na maioria das capitais entre o número de equipes que aderiram ao PMAQ-AB e o número de apoiadores existentes para as mesmas. Identificaram-se situações em que o número total de apoiadores institucionais, informados pelas gestões, foi superior ao número de equipes que aderiram ao PMAQ- $\mathrm{AB}$, como é o caso das capitais de João Pessoa, Manaus, Rio Branco, Cuiabá e Campo Grande.

Em relação à quantidade máxima de equipes por apoiador institucional, evidencia-se que, em 55\% das capitais, os apoiadores se responsabilizavam por 
mais de dez equipes, chegando a apoiar até trinta equipes, como é o caso de Fortaleza. A menor proporção equipe/apoiador foi encontrada em Rio Branco e João Pessoa. Duas capitais (Vitória e Brasília) não informaram esses dados, ou não souberam responder.

No que diz respeito à cobertura do apoio institucional para as equipes que aderiram ao PMAQ em cada capital, três gestores não responderam ou não souberam responder (Rio de Janeiro, Florianópolis e Brasília). As demais capitais apresentaram duas situações distintas: nos casos em que a gestão informou apoiar um número de equipes superior ao número de equipes que aderiram ao PMAQ (Campo Grande e Porto Alegre); e nos casos em que o município possui grande potencial de apoio pelo número e carga horária de apoiadores informados, mas apresentam número muito 'desproporcional' de apoio às equipes [Cuiabá (0), São Paulo (9) e Curitiba (4)].

Sobre a carga horária do apoiador, pode-se observar que a maioria dos gestores $(68,2 \%)$ afirmou possuir apoiadores com carga horária de 40 horas semanais. Com carga horária de 12 a 20 horas semanais, encontramos 9,1\% dos apoiadores e em 13,6\% das capitais os apoiadores possuem carga horária variando entre 4 e 8 horas semanais, destinadas a essa função. Duas capitais (Porto Velho e Brasília) não souberam ou não responderam essa questão.

\section{Tabela 2}

\begin{tabular}{|c|c|c|c|c|c|}
\hline $\begin{array}{l}\text { Capitais } \\
\text { brasileiras }\end{array}$ & $\begin{array}{c}{ }^{*} \text { Quantidade } \\
\text { total de equipes } \\
\text { por capitais que } \\
\text { aderiram ao PMAQ }\end{array}$ & $\begin{array}{c}{ }^{* *} \text { Quantidade total de } \\
\text { apoiadores institucionais } \\
\text { permanentes para } \\
\text { as equipes }\end{array}$ & $\begin{array}{l}{ }^{* *} \text { Quantidade } \\
\text { máxima de equipes } \\
\text { por apoiador } \\
\text { institucional }\end{array}$ & $\begin{array}{c}\text { **Número de } \\
\text { equipes apoiadas } \\
\text { que participaram } \\
\text { do PMAQ }\end{array}$ & $\begin{array}{c}{ }^{* *} \text { Carga horária } \\
\text { semanal de dedicação } \\
\text { ao trabalho de } \\
\text { apoio institucional }\end{array}$ \\
\hline \multicolumn{6}{|l|}{ Norte } \\
\hline Porto Velho & 57 & 5 & 25 & 25 & - \\
\hline Rio Branco & 11 & 27 & 2 & 11 & 12 \\
\hline Manaus & 34 & 110 & 4 & 34 & 6 \\
\hline Belém & 32 & 5 & 29 & 14 & 40 \\
\hline Palmas & 42 & 3 & 16 & 15 & 40 \\
\hline \multicolumn{6}{|l|}{ Nordeste } \\
\hline Fortaleza & 52 & 20 & 30 & 50 & 40 \\
\hline Natal & 31 & 4 & 8 & 8 & 8 \\
\hline João Pessoa & 88 & 141 & 2 & 88 & 40 \\
\hline Recife & 226 & 12 & 27 & 25 & 40 \\
\hline Aracajú & 45 & 8 & 21 & 11 & 40 \\
\hline Salvador & 55 & 8 & 16 & 35 & 40 \\
\hline \multicolumn{6}{|l|}{ Sudeste } \\
\hline Belo Horizonte & 534 & 359 & 6 & 537 & 40 \\
\hline Vitória & 75 & 41 & - & 75 & 4 \\
\hline Rio de Janeiro & 324 & 151 & 10 & - & 40 \\
\hline São Paulo & 790 & 332 & 12 & 9 & 40 \\
\hline \multicolumn{6}{|l|}{ Sul } \\
\hline Curitiba & 201 & 109 & 4 & 4 & 40 \\
\hline
\end{tabular}


Continuação - Tabela 2

\begin{tabular}{|c|c|c|c|c|c|}
\hline \multicolumn{6}{|c|}{$\begin{array}{l}\text { Quantidade de equipes que aderiram ao PMAQ, quantidade total de apoiadores institucionais permanentes para as equipes, quantidade máxima de } \\
\text { equipes por apoiador institucional e número de equipes apoiadas que participaram do PMAQ segundo a gestão. Capitais do Brasil, } 2012 .\end{array}$} \\
\hline $\begin{array}{l}\text { Capitais } \\
\text { brasileiras }\end{array}$ & $\begin{array}{c}{ }^{*} \text { Quantidade } \\
\text { total de equipes } \\
\text { por capitais que } \\
\text { aderiram ao PMAQ }\end{array}$ & $\begin{array}{l}* * \text { Quantidade total de } \\
\text { apoiadores institucionais } \\
\text { permanentes para } \\
\text { as equipes }\end{array}$ & $\begin{array}{l}{ }^{* *} \text { Quantidade } \\
\text { máxima de equipes } \\
\text { por apoiador } \\
\text { institucional }\end{array}$ & $\begin{array}{c}\text { **Número de } \\
\text { equipes apoiadas } \\
\text { que participaram } \\
\text { do PMAQ }\end{array}$ & $\begin{array}{c}\text { **Carga horária } \\
\text { semanal de dedicação } \\
\text { ao trabalho de } \\
\text { apoio institucional }\end{array}$ \\
\hline Florianópolis & 90 & 5 & 29 & - & 40 \\
\hline Porto Alegre & 54 & 16 & 10 & 163 & 40 \\
\hline \multicolumn{6}{|l|}{ Centro-Oeste } \\
\hline Campo Grande & 2 & 4 & 20 & 14 & 20 \\
\hline Cuiabá & 4 & 9 & 13 & 0 & 40 \\
\hline Goiânia & 152 & 42 & 9 & 9 & 40 \\
\hline Brasília & 28 & - & - & - & - \\
\hline
\end{tabular}

Fonte: Elaborado pelos autores, a partir do banco do módulo II e IV do PMAQ (2012).

Nota 1: * Módulo Il; ** Módulo IV.

Nota 2: PMAQ: Programa de Melhoria da Qualidade e do Acesso.

\section{O processo de trabalho do apoiador institucional}

Ao analisar que profissionais realizam o apoio ao processo de planejamento e organização do processo de trabalho (Gráfico 2), os resultados evidenciaram que o apoiador institucional e outros profissionais da gestão são os que mais apoiam as equipes, tanto na média nacional quanto nas capitais. Respectivamente, esses valores foram de $48,4 \%$ e $50,0 \%$ no Brasil e $62,4 \%$ e $52,7 \%$ nas capitais, com uma diferença de 14 pontos percentuais para mais, no percentual de profissionais que exercem, especificamente, a função de apoiador institucional nas capitais brasileiras. Os profissionais da vigilância em saúde aparecem com o percentual muito próximo em ambos os contextos analisados.

\section{Gráfico 2}

Profissionais que realizam o apoio para o planejamento e a organização do processo de trabalho das equipes, segundo informação das equipes. Capitais do Brasil, 2012

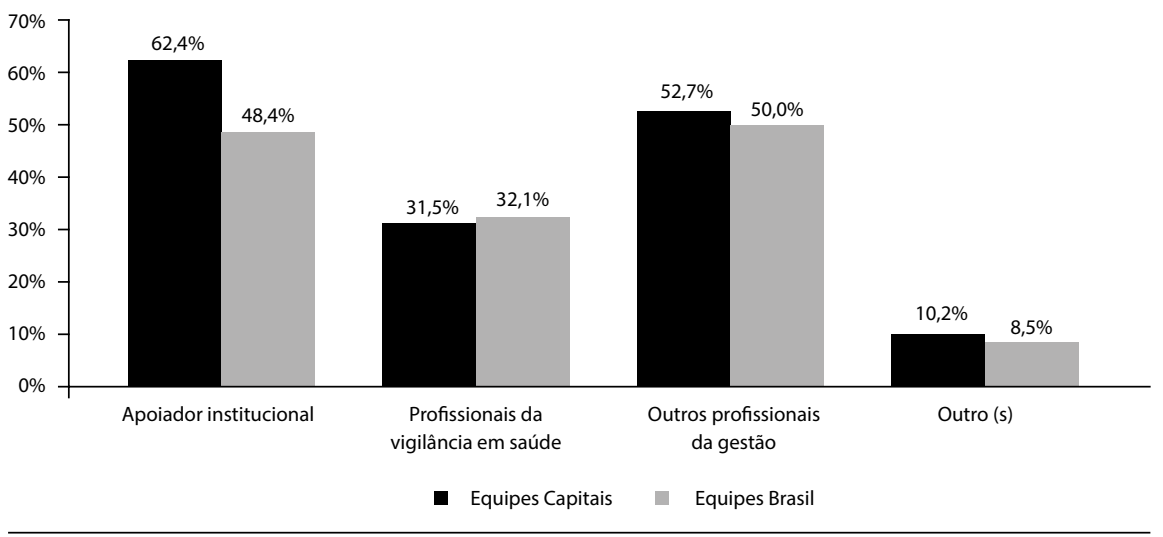

Fonte: Elaborado pelos autores, a partir do banco do módulo II PMAQ (2012). 
O desempenho do apoiador foi considerado bom ou muito bom para a maior parte das equipes investigadas. No conjunto das capitais brasileiras, observou-se que os processos melhor avaliados dizem respeito à contribuição do apoiador nos momentos de autoavaliação $(59,1 \%)$, seguido pela sua participação nas reuniões $(57,0 \%)$. Entretanto, quando considerada a totalidade de equipes no território nacional, identificou-se que todos os percentuais foram abaixo de $50 \%$. O apoiador é mais bem avaliado em relação a sua contribuição na qualificação do processo de trabalho, no enfrentamento dos problemas $(49,2 \%)$ e no contato que o apoiador mantém com a equipe $(46,1 \%)$.

Dentre as atividades desenvolvidas pelo apoiador, segundo as equipes das capitais investigadas (Tabela 3), as maiores frequências dizem respeito a: discussão do processo de trabalho da equipe, e também, do próprio apoio institucional (67,2\%); apoio ao monitoramento e à avaliação das informações e indicadores $(62,5 \%)$ e o apoio à autoavaliação das equipes $(61,1 \%)$. Percentuais discretamente maiores foram observados em relação à média nacional.

Chama a atenção, como a atividade menos desenvolvida, o apoio ao planejamento e à organização de trabalho da equipe, que ocorre somente em $26,7 \%$ nas capitais e $27,5 \%$ no Brasil. Em relação à avaliação compartilhada com as equipes de progressos e resultados, a atuação do apoiador tem sido mediana (53,1\% nas capitais e 56,9\% na média nacional). Outras atividades, também desenvolvidas pelo apoiador e que aparecem com percentual abaixo de $50 \%$ nas capitais, são da educação permanente $(49,6 \%)$, a participação do apoiador nas reuniões com a equipe $(49,3 \%)$ e as oficinas com objetivos específicos definidos $(49,4 \%)$. Duas dessas atividades destacam-se pelas variações percentuais maiores entre a média nacional e das capitais: a participação do apoiador nas reuniões com equipe e oficina com objetivo específico definido.

Tabela 3

\begin{tabular}{lcc}
\hline Atividades realizadas pelo apoiador institucional, segundo as equipes. Capitais do Brasil, 2012. \\
\hline Atividades realizadas pelo apoiador institucional & $\begin{array}{c}\text { Equipes } \\
\text { Capitais } \\
\mathbf{n = 2 9 4 1}\end{array}$ & $\begin{array}{c}\text { Equipes } \\
\text { Brasil } \\
\mathbf{n}=\mathbf{1 7 2 0 2}\end{array}$ \\
\hline Discussão com o apoiador institucional do processo & 1975 & 12895 \\
de trabalho da equipe de atenção básica e, também, & $67,15 \%$ & $75,00 \%$ \\
do próprio apoio institucional & 1798 & 11560 \\
Apoio dirigido à autoavaliação das equipes de & $61,13 \%$ & $67,20 \%$ \\
atenção básica & 1837 & 11774 \\
Apoio dirigido ao monitoramento e avaliação de & $62,5 \%$ & $68,40 \%$ \\
informações e indicadores & 790 & 4725 \\
Apoio ao planejamento e à organização da equipe & $26,7 \%$ & $27,50 \%$ \\
Avaliação compartilhada apoiador institucional/ & 1562 & 9791 \\
equipe de progressos e resultados & $53,11 \%$ & $56,90 \%$ \\
\hline
\end{tabular}


Continuação - Tabela 3

\begin{tabular}{lcc}
\hline Atividades realizadas pelo apoiador institucional, segundo as equipes. Capitais do Brasil, 2012. \\
\hline Atividades realizadas pelo apoiador institucional & $\begin{array}{c}\text { Equipes } \\
\text { Capitais } \\
\mathbf{n = 2 9 4 1}\end{array}$ & $\begin{array}{c}\text { Equipes } \\
\text { Brasil }\end{array}$ \\
& 1453 & $\mathbf{n = 1 7 2 0 2}$ \\
\hline Oficina com objetivo específico definido & $49,4 \%$ & 6956 \\
Educação permanente & 1461 & $40,40 \%$ \\
& $49,68 \%$ & 9069 \\
Participação do apoio institucional nas & 1452 & $52,70 \%$ \\
reuniões com a equipe & $49,37 \%$ & 10511 \\
& 96 & $61,10 \%$ \\
\hline
\end{tabular}

Fonte: Elaborado pelos autores, a partir do banco do módulo II PMAQ (2012).

Também em relação ao fazer do apoiador institucional, do mesmo modo, no módulo IV, foi solicitado que o gestor apontasse, dentre as alternativas do formulário, a(as) responsabilidade(s)/atribuições do(s) profissional(ais) do apoio institucional, no município. Na maioria das capitais, a gestão considerou quase todas as alternativas apresentadas como atribuição dos apoiadores, atingindo-se, desse modo, um alto percentual, que variou de $85,7 \%$ a $95,2 \%$. No entanto, verificou-se como de menor importância para os gestores das capitais a articulação de ações de apoio matricial para os Núcleos de Apoio à Saúde da Família (NASF) e a outros serviços da rede $(76,2 \%)$ e, principalmente, o suporte à construção de projetos terapêuticos singulares, a partir de casos ou situações que mobilizam ou desafiam a equipe $(57,1 \%)$.

\section{Apoio da gestão na administração e planejamento dos processos de trabalho das equipes}

Em relação aos processos desenvolvidos pelas equipes e que são apoiados pela gestão (Gráfico 3), observou-se que não houve diferença significativa entre os processos investigados, tanto na totalidade das equipes investigadas, quanto nas capitais. Como destaque, e acima de $90 \%$, encontrou-se o apoio à organização do processo de trabalho em função da implantação ou qualificação dos padrões de acesso e qualidade do PMAQ. No Brasil, os menores percentuais foram atribuídos ao planejamento e organização do processo de trabalho da equipe $(74,2 \%)$ e, nas capitais, os processos menos apoiados pela gestão $(77,9 \%$ ) foram os relacionados à discussão dos dados de monitoramento do Sistema de Informação da Atenção Básica (SIAB). 


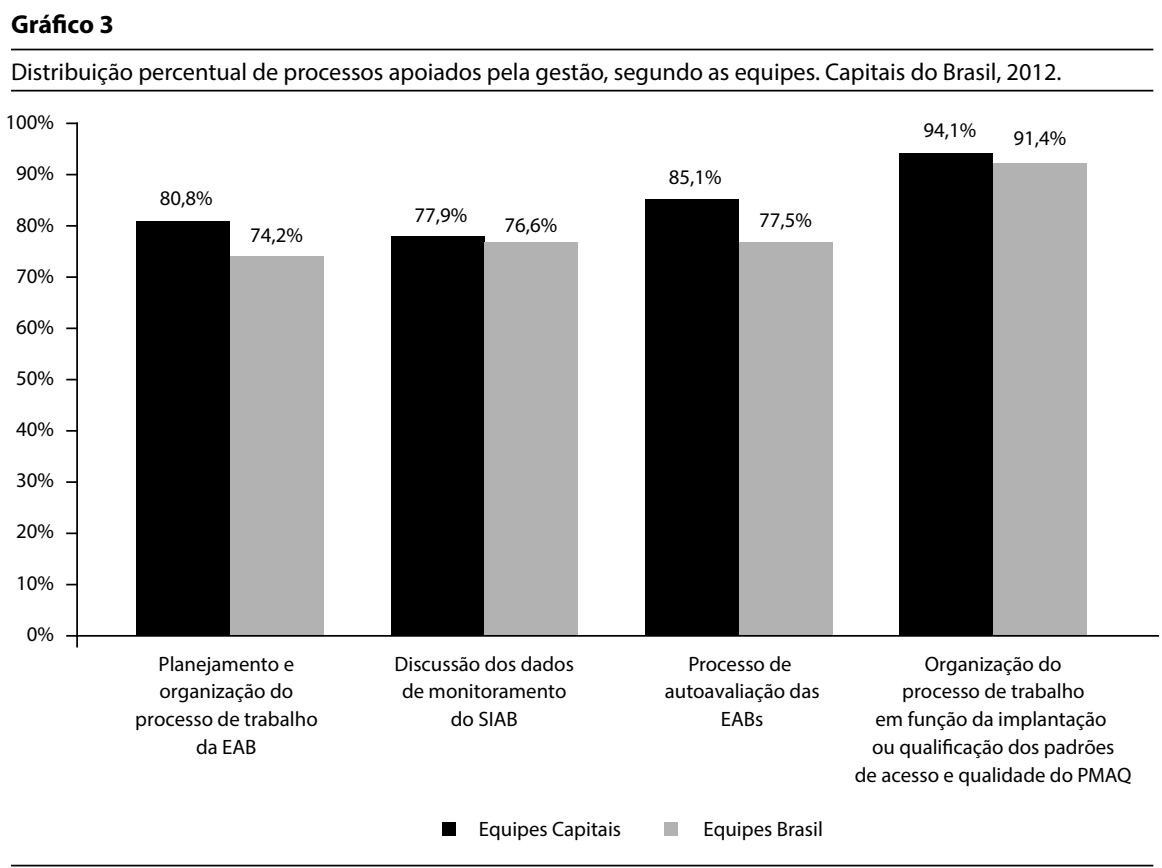

Fonte: Elaborado pelos autores, a partir do banco do módulo II PMAQ (2012).

Nota: EABs - Equipes de atenção básica; SIAB - Sistema de Informação da Atenção Básica; PMAQ-AB - Programa de Melhoria da Qualidade e do Acesso da Atenção Básica.

\section{Discussão}

Em relação à dimensão 'características do apoio institucional', observou-se que uma quantidade significativa de respondentes afirmou receber apoio permanente de uma equipe ou pessoa da Secretaria Municipal de Saúde e que este apoio já existia mesmo antes da adesão da equipe ao PMAQ-AB.

Entretanto, embora se reconheça o estímulo às gestões municipais para a implantação do apoio institucional às equipes, o que se percebeu a partir dos dados analisados foi que, nesse primeiro ciclo, o PMAQ-AB pouco contribuiu para a indução do apoio na $\mathrm{AB}$. Esse fato é identificado, principalmente, nas capitais brasileiras embora em certa medida, as equipes reconheçam como apoio institucional o suporte que recebem das gestões.

Quando esses municípios foram agrupados por região geográfica ou no conjunto das capitais brasileiras, observou-se uma variação considerável. Tal ocorrência revelou que, em relação ao apoio institucional, o reconhecimento da sua importância para a atenção básica, a prioridade dada à sua implantação e, também, o nível de sua institucionalização em cada município têm ocorrido de forma bastante diferenciada.

O maior percentual de apoio nas capitais da região do Centro-Oeste foi um dado também encontrado por Cruz et al. (2014), ao analisarem os dados 
da avaliação externa do PMAQ-AB por regiões brasileiras, no que diz respeito à oferta de apoio institucional para o planejamento e organização do processo de trabalho. Os autores concluíram ainda que a menor frequência do apoio ocorreu no norte do Brasil. O mesmo estudo revelou que, levando em consideração a população dos municípios do Centro-Oeste brasileiro, as equipes das cidades com maiores populações (acima de 100 mil habitantes) foram as que tiveram menores frequências do apoio institucional. Santos et al. (2015) chamam a atenção para a forte associação entre o grau de apoio institucional recebido pelas equipes e sua certificação com desempenho ótimo.

A percepção de fragilidades na oferta do apoio institucional - equipes do norte do país - foi também registrada por Garnelo et al. (2013), quando afirmam haver um entendimento desigual por parte dos gestores sobre a importância do PMAQ-AB na qualificação da atenção básica, e ainda no compromisso firmado com a contratualização de suas equipes. A despeito da forma de contato do apoiador com as equipes ser predominantemente presencial tanto no Brasil como em nível de capitais, o contato via telefone ainda é uma realidade muito presente na atenção básica. Destaca-se, entretanto, o baixo contato do apoiador com as equipes via internet. Esse dado pode ser identificado como um fator dificultador no suporte às equipes, já que o acesso às plataformas virtuais possibilitaria que trabalhadores e gestores da atenção básica, com uso de recursos da tecnologia da informação, estreitassem vínculos institucionais, compartilhassem saberes e práticas, esclarecessem dúvidas e fossem orientados em salas virtuais, de forma que pudessem qualificar o cuidado e a gestão do cuidado. Registra-se ainda a sua importância como estratégia de educação permanente, sobretudo quando o apoiador precisa se deslocar para grandes distâncias para apoiar presencialmente as equipes ou quando o número de apoiadores é insuficiente no município.

A inclusão de tecnologias da informação e comunicação guarda estreita relação com as atuais condições de infraestrutura das unidades de saúde em grande parte dos municípios brasileiros.

Simões (2014, p. 5), ao estudar os trabalhadores das unidades de Saúde da Família inseridos em situações de grandes vulnerabilidades no município de Manaus, identificou que tais contextos interferem "muito menos nas práticas laborais dos trabalhadores do que a infraestrutura inadequada das condições de trabalho, como a falta de materiais e equipamentos necessários para a produção de saúde no território".

Portanto, investir nas condições de infraestrutura das unidades básicas de saúde (UBSs) na perspectiva ampliada da ambiência, trazida pelo HumanizaSUS, pode ser um caminho, considerando o espaço físico como espaço social profissional e relacional capaz de propiciar uma atenção acolhedora, resolutiva e humana (Brasil, 2010).

Com relação à quantidade de apoiadores institucionais, ressalta-se que, apesar de ser um questionamento feito tanto para as equipes quanto para o 
gestor, não há proposta para o dimensionamento do apoiador institucional para a atenção básica.

Observa-se que grande parte das equipes referiu receber apoio institucional e possuir até cinco apoiadores na sua equipe. No entanto, ainda que com um percentual reduzido, existiram equipes tanto nacionalmente quanto nas capitais, que afirmaram receber apoio de seis a dez apoiadores. Esse dado conduz a alguns questionamentos: $\mathrm{O}$ que as equipes têm denominado ser apoio institucional? Que modelo de apoio é predominante atualmente na atenção básica? Que prioridade tem sido dada pela gestão para o apoio institucional como ferramenta inovadora para alterar modelos de gestão e de cuidado no SUS?

Embora a gestão das capitais tenha informado que grande parte dos apoiadores dedica 40 horas semanais para a função apoio, ainda há situações em que a carga horária pode ser insuficiente, quando consideradas as características da metodologia de Apoio Paideia e as inúmeras situações em que as equipes necessitam de suporte.

Ao confrontar dados dos profissionais das capitais com as informações das gestões desses mesmos municípios, verifica-se uma divergência em relação aos dados fornecidos pelas equipes, uma vez que, para a gestão, em mais de $50 \%$ dos casos, os apoiadores se responsabilizam por mais de dez equipes, chegando a ficar responsável por até trinta equipes.

Costa (2009), ao estudar o processo de trabalho da equipe de apoio institucional no estado da Bahia, chama a atenção tanto para a existência de apoiadores com intensa carga horária de trabalho quanto para a precariedade de vínculos empregatícios, salientando que, em algumas situações, os apoiadores não conseguem cumprir a agenda junto às equipes, devido às grandes demandas do nível central.

Do mesmo modo, Fernandes e Figueiredo (2014, p. 290), ao refletirem sobre o cotidiano dos apoiadores do SUS em Campinas, constataram que, nos últimos anos, tem havido certo "desinvestimento político no apoio, como metodologia de trabalho". Tal situação, na visão dos autores, dificulta o fazer de apoiadores institucionais, no sentido de não poderem desenvolver o seu trabalho, de acordo com a metodologia apoio. Outras dificuldades encontradas pelos apoiadores em um município paulista foram: rotatividade de gestor local e da equipe de apoiadores e a ausência de suporte do próprio grupo de apoio (Bellini, Pio e Chirelli, 2016).

Para Paulon, Pasche e Righi (2014, p. 812-813), a função apoio “depende de certa estabilidade", que se verifica, (...) dentre outros, "na contratação de um certo número de encontros". Nesses encontros, apoiador e apoiados precisam trazer consigo o desejo da mudança, de abrir-se aos deslocamentos, que serão desencadeados pelo apoio, de libertar-se de processos instituídos, arraigados na cotidianidade, assim como de saberes e poderes demarcados, muitas vezes por processos históricos das profissões ou por leis e normas presentes na instituição. 
No entanto, nem tudo que se faz com o nome apoio é apoio! “O apoio se diferencia de uma visita, de um contato, ou mesmo de ação que é típica de assessorias e consultorias: entrar em contato com coletivos para anunciar a eles, desde um suposto saber, ou que o grupo deve fazer" (Paulon, Pasche e Righi, 2014, p. 813).

Em relação ao percentual de cobertura do apoio institucional para as equipes que aderiram ao PMAQ em cada capital, percebeu-se que os dados se mostraram frágeis, em virtude das inconsistências apresentadas, o que dificultou sua análise. Tal fato nos faz questionar sobre o envolvimento e o compromisso da gestão da atenção, no que diz respeito à implantação do apoio institucional no município, bem como de uma possível fragilidade do sistema de informação em relação à gestão do trabalho, especificamente, em relação a informações dos profissionais que assumem a função apoio.

No que se refere aos profissionais que realizam o apoio ao processo de planejamento e organização do processo de trabalho, a experiência brasileira tem demonstrado uma diversificação nos modelos de implementação e operacionalização do apoio institucional, mas, de modo geral, tanto os apoiadores quanto os apoiados têm sido definidos previamente pela instituição (Oliveira, 2012).

Com base nos dados, identificou-se que, no cenário da atenção básica e, principalmente, nas capitais brasileiras, o apoio ao planejamento e a organização do processo de trabalho tem ocorrido prioritariamente pelo apoiador institucional e por outros profissionais da gestão, seguidos dos profissionais da vigilância em saúde. Cruz et al. (2014) chegaram a conclusões semelhantes, quando analisaram essa mesma variável por estrato populacional e regiões brasileiras, embora façam uma ressalva de que é na região Sul, mesmo considerando todos os portes populacionais, que se encontra um número mais expressivo de apoiadores, que são profissionais da vigilância em saúde.

Nos municípios que criaram o cargo do apoiador institucional, esses trabalhadores assumem a função apoio, substituindo os antigos supervisores/fiscalizadores do trabalho das equipes em atividades programáticas, estabelecendo uma relação hierárquica com diferentes atores, mas, ao mesmo tempo, respondendo a uma chefia que lhes é superior, por vezes vinculadas diretamente ao próprio secretário de saúde (Oliveira, 2012).

Nessas experiências, o apoiador se constitui na relação com seus apoiados como um mediador formal. Não seria um problema, se não fosse a forte tendência à fixidez dos papéis de apoiador e de apoiado, correndo-se o risco de se tornar um processo unilateral e burocratizado.

Portanto, importa salientar que, independente do lugar em que se inscreve o apoiador institucional, há de se entender que "o que mais claramente delimita a definição do apoio institucional é a cogestão" (Paulon, Pasche e Righi, 2014, p. 815), ou seja, o seu caráter democrático inscrito na possibilidade de compartilhar compromissos com as equipes, de forma que as adversidades, advindas do cotidiano, possam ser melhor administradas ou superadas. 
A despeito da compreensão da simultaneidade em que ocorrem as atividades realizadas pelo apoiador, quando estas são analisadas distintamente, considera-se possível que a ênfase a ações de apoio ao monitoramento e à avaliação de informações e indicadores e ao apoio à autoavaliação das equipes tenham sido influenciadas pela fase II (desenvolvimento) do PMAQ-AB, na qual a autoavaliação e o monitoramento compuseram um conjunto de ações a serem desenvolvidas pelo apoiador para auxiliar as equipes antes da fase da avaliação externa.

A cisão do planejamento com o monitoramento e avaliação foi um dado bastante relevante, encontrado na avaliação externa, tanto nas capitais quanto no conjunto de todas as equipes brasileiras. Isso porque, ao contrário do monitoramento e avaliação, os respondentes afirmaram que, dentre as atividades menos desenvolvidas pelo apoiador, está o suporte ao planejamento e à organização de trabalho da equipe, presente somente em menos de $30 \%$ das equipes estudadas. Achados semelhantes foram encontrados por Cruz et al. (2014) e Santos et al. (2015) quando analisam essa mesma variável a partir dos dados do PMAQ-AB.

Ao realizar estudos em cenários da atenção básica, Mishima (2003), Kawata et al. (2009) e Sarti et al. $(2008$; 2012) confirmaram essa tendência, ressaltando que, em muitos casos, houve envolvimento apenas de alguns profissionais nesses processos. O monitoramento e a avaliação ocorreram desarticulados do planejamento das ações foram realizados de modo pontual, apenas para cumprir etapas normativas de programas de saúde.

Outro dado que reforça a fragmentação da avaliação e a fragilidade da cogestão é quando se identifica que o compartilhamento do apoiador com as equipes de progressos e resultados tem ocorrido com frequência mediana, principalmente nas capitais brasileiras.

É possível que a participação dos apoiadores na discussão do processo de trabalho da equipe tenha ocorrido principalmente em virtude da necessidade de dar suporte na organização do processo de trabalho de ações vinculadas às metas e compromissos pactuados com a gestão municipal, para qualificar a atenção básica durante o período de certificação. Isso porque evidencia-se que a participação do apoiador nas reuniões com a equipe nas oficinas com objetivos específicos definidos e na educação permanente foram atividades com menor frequência, ocorrendo em menos da metade das equipes das capitais brasileiras.

Ao se analisar a realização de reuniões pelas Equipes de Atenção Básica (EAB), que aderiram ao PMAQ-AB no primeiro ciclo, Cruz et al. (2014) afirmam que, segundo os respondentes, independente do extrato populacional do município, mais de $90 \%$ das equipes realizam reuniões de equipes. Segundo as autoras, considerando todas as regiões brasileiras, apenas $38,0 \%$ das equipes realizam reuniões semanais. As reuniões quinzenais representam 17,0\%; as mensais, $32,5 \%$; e 12,5\% das equipes afirmaram não haver periodicidade definida para as reuniões de equipe. 
Os achados dessa investigação são preocupantes, ainda mais se forem respaldados pelo desempenho das equipes, em relação a suas reuniões, trazidos por Cruz et al. (2014). Para os padrões de qualidade, esperados pelas equipes, essas deveriam se reunir periodicamente (semanal ou quinzenal) em reuniões com duração média de 2 horas (Brasil, 2012).

Na visão de Campos (2000) e Grando e Dall'agnol (2010), constituem-se, portanto, em 'espaços coletivos', em que o grupo analisa, define tarefas e elabora projetos de intervenção. No entanto, muitas vezes, a depender da concepção e da condução que se assume, esses encontros podem deixar de ser espaços de criação e recriação do saber/fazer dos trabalhadores, para se constituírem em momentos enfadonhos, burocráticos e normativos, com pouca capacidade de análise para tomadas de decisões.

Vale salientar que, independente da atividade desenvolvida pelo apoiador e de como ela tem ocorrido, o seu desempenho foi considerado pelos respondentes como bom ou muito bom para a maior parte das equipes da atenção básica. Nas capitais, as equipes consideram o apoio à autoavaliação melhor avaliado; já nacionalmente, a contribuição do apoiador, na qualificação do processo de trabalho e no enfrentamento dos problemas, obteve maior destaque.

Verifica-se que a institucionalização do apoio é um processo não linear, contraditório, com avanços e recuos. Porém, no cotidiano da atenção básica, marcado pelo estresse, conflito e, muitas vezes, com espaços bem definidos de concentração de saberes e poderes, parece ser demasiadamente importante para as equipes o simples fato de ter um ator institucional, que apoie, sustente e empurre o grupo nos seus processos de trabalho, trazendo-lhe algo externo (Campos, 2003). Em recente estudo sobre a experimentação do apoio no Distrito Federal, evidenciou-se que tais práticas contribuíram para qualificar os processos de gestão democrática e a assistência na atenção básica (Cardoso, Oliveira e Furlan, 2016).

Falleiro et al. (2014, p. 23) consideram, no contexto do processo de trabalho do apoiador, a educação permanente como "principal ferramenta tanto para promover a ampliação da capacidade de reflexão e de análise dos coletivos quanto para tornar possível a sua própria formação" do seu fazer cotidiano.

A despeito do potencial da educação permanente em ampliar a capacidade crítica reflexiva da equipe e aumentar a capacidade técnica dos trabalhadores para lidar com problemas do cotidiano, observou-se que tanto as atividades de educação permanente quanto as oficinas com objetivos específicos definidos são atividades pouco ofertadas às equipes por meio do apoio institucional Na média das capitais, a educação permanente alcançou percentual menor do que a média do conjunto das equipes brasileiras; já as oficinas, embora também com baixo percentual de oferta, ocorreram com maior frequência, considerando a média nacional.

Talvez esses dados reforcem ainda mais o argumento inicial de que, em relação às atividades desenvolvidas pelo apoiador, a maior parte delas se voltou 
a dar suporte às equipes nos processos de monitoramento e avaliação de forma fragmentada e desarticulada do planejamento e dos processos de educação permanente, o que reforça o viés/desvio da função apoio, em que em muitos casos, como bem afirmam Pereira Junior e Campos (2014, p. 904), os apoiadores são utilizados "muito mais como agentes de implantação dos programas do MS".

Identificou-se que, embora as equipes informem receber apoio da gestão em todos os processos investigados, a organização do processo de trabalho em função da implantação ou qualificação dos padrões de acesso e qualidade do PMAQ e a autoavaliação das equipes foram os mais apoiados pela gestão. Especificamente nas capitais, a prioridade menor foi dada ao planejamento e organização de trabalho da equipe e, por último, veio a discussão dos dados de monitoramento do SIAB.

A despeito da importância de que em todos esses processos os profissionais sintam- se apoiados pelos gestores da atenção básica, alguns aspectos nos chamam atenção por se relacionarem ao nível de normatividade da função apoio presente na atenção básica nesse momento, em particular.

Para os profissionais respondentes, o apoio ofertado pela gestão, segundo as equipes, ocorre prioritariamente (mais de 90\%) voltado para a organização do processo de trabalho em função da implantação ou qualificação dos padrões de acesso e qualidade do PMAQ.

Duas questões são colocadas: a primeira, como saber que outros processos a gestão apoia ou não? A segunda, os questionamentos feitos aos profissionais das equipes guardam relação direta com as fases do PMAQ-AB? Se a função apoio se exerce sustentada pelo elemento fundante da cogestão, não seria imprescindível que as questões, presentes no instrumento de coleta, possibilitassem dar pistas para identificar a presença (ou não) das diretrizes básicas do apoio, como a democracia institucional e autonomia dos sujeitos?

Tal fato expõe o risco de, além de superficializar a avaliação do apoio institucional na atenção básica, tornar o apoio institucional um processo pontual e com pouca potência de indução de processos instituintes.

A necessidade de se apreender, na avaliação do apoio institucional, o aspecto fundante da cogestão é reforçado por Paixão e Tavares (2014). As autoras, ao analisarem o trabalho de apoio em um município metropolitano de São Paulo, reconhecem o enfraquecimento da estratégia de apoio no município estudado, "dada a pouca valorização dos espaços de gestão compartilhada, nos quais os trabalhadores se poriam de maneira interrogativa, dialógica, ao darem sentido para suas práticas" (Paixão e Tavares, 2014, p. 856).

Vale registrar que todas as alternativas presentes no instrumento on line corresponderam às ações do apoio institucional para o enfrentamento dos principais desafios e para a qualificação da atenção básica, os quais foram incorporados na $\mathrm{AMAQ}-\mathrm{AB}$, na dimensão gestão da atenção básica e subdimensão apoio institucional (Brasil, 2012, p. 42). 
Quase a totalidade das gestões da atenção básica identificou como de responsabilidade do apoiador as ações, que são apresentadas no instrumento. É provável que a quantidade de valores percentuais, acima de $90 \%$, tenha sido influenciada pelo modo como essa questão foi apresentada no instrumento, o que pode ter contribuído para indução de respostas afirmativas. Pode-se pensar ainda que, apesar do fato de a maioria das alternativas serem reconhecidas pelas gestões como responsabilidades do apoiador institucional, não significa dizer que essas ações tenham sido implementadas na prática. Nesse quesito, é importante destacar que a facilitação da organização de intervenções intersetoriais e a articulação de ações de apoio institucional junto aos NASFs e a outros serviços da rede tiveram um percentual de escolha um pouco menor, talvez pelo município ainda apresentar fragilidades na estruturação da rede de atenção nas capitais, como também possíveis debilidades no apoio integrado na região.

No entanto, uma ressalva se faz em relação à última prioridade de escolha, como atribuição do apoiador institucional para todas as gestões das capitais analisadas: o suporte à construção de projetos terapêuticos singulares (PTS), a partir de casos ou situações que mobilizam ou desafiam a equipe.

O PTS constitui-se como uma importante ferramenta na gestão do cuidado, por possuir o potencial de estabelecer relações dialógicas e horizontalizadas entre os profissionais envolvidos e possibilitar, desse modo, o compartilhamento de casos e o acompanhamento longitudinal de responsabilidade dessas equipes. É definido por Oliveira (2010, p. 94) como um "movimento de coprodução e de cogestão do processo terapêutico de um Sujeito Singular, individual ou coletivo, em situação de vulnerabilidade", portanto uma ferramenta potente e complexa para a construção da democracia institucional.

\section{Considerações finais}

Como limite do estudo, destaca-se o fato de que no momento em que os entrevistados eram questionados sobre a existência de Apoio institucional permanente de uma equipe ou pessoa da $S M S$, não foi possível identificar, em virtude das características do instrumento de coleta, qual a concepção de apoio dos entrevistados e se esse entendimento era coincidente com as características do Apoio Paideia, proposto para a atenção básica pelo MS. Dessa forma, reitera-se que, a despeito da importância do apoio institucional ser uma das dimensões avaliadas pelo $\mathrm{PMAQ}-\mathrm{AB}$, há necessidade de prosseguirmos investigando outras dimensões do apoio como, por exemplo, como e com que atores ocorrem as rodas de apoio e qual a autonomia do apoiador institucional para disparar, junto com as equipes, processos instituintes. Tais respostas podem dar pistas para identificar o potencial democratizante do apoio institucional frente ao seu processo de institucionalização na atenção básica. 


\section{Colaboradores}

Lygia Maria de Figueiredo Melo realizou a coleta de dados e participou de todas as etapas da pesquisa e da produção e revisão do artigo; Claudia Santos Martiniano auxiliou na auxiliou na coleta de dados, redação e revisão final do artigo, Ardigleusa Alves Coelho e Marize Barros de Souza auxiliaram na coleta de dados e na produção final do texto; Themis Xavier de Albuquerque Pinheiro participou da produção final do texto. Paulo de Medeiros Rocha participou da orientação da pesquisa e produção do texto. Não há, por parte dos autores, conflito de interesses com relação à pesquisa.

Resumen El objetivo de esta investigación cuantitativa descriptiva fue analizar el apoyo institucional en los equipos adheridos al Programa de Mejora del Acceso y la Calidad de la Atención Básica. La recolección de datos se realizó en el período de febrero a octubre de 2014, a partir del banco de datos de evaluación externa del programa. La muestra comprendió a 2.941 participantes del módulo II y los 22 gestores que respondieron al módulo IV (on line). Se analizaron las variables mediante estadística descriptiva, con software IBM SPSS y los resultados se organizaron y agruparon según tres dimensiones: características del apoyo institucional; proceso de trabajo del apoyador institucional y apoyo de la gestión en la administración y planeamiento de los procesos de trabajo. Se observó que el apoyo es una realidad en la atención básica, no obstante, se identificó, en las acciones apoyadas, un rasgo normalizador y burocrático. El apoyador institucional fue evaluado positivamente, aunque se encuentre sobrecargado por el número excesivo de equipos bajo su responsabilidad, poniendo de manifiesto la necesidad de un dimensionamiento que tome en consideración el modo de operar de la función apoyo. En virtud de las características del instrumento de recolección, no fue posible identificar cuál es la concepción de apoyo de los entrevistados, constituyendo un límite del estudio. Palabras clave gestión en salud; apoyo institucional; atención básica.

\section{Notas}

${ }^{1}$ Escola de Saúde da Universidade Federal do Rio Grande do Norte, Programa de Pós-Graduação em Práticas de Saúde e Educação. Natal, Rio Grande do Norte, Brasil. <lygia.melo@yahoo.com.br> Correspondência: Escola de Saúde da Universidade Federal do Rio Grande do Norte, Avenida Senador Salgado Filho, s/n - Lagoa Nova, Natal, Rio Grande do Norte, 59078-970

2 Universidade Estadual da Paraíba, Departamento de Enfermagem, Programa de Pós-Graduação em Saúde Pública, Campina Grande, Paraíba, Brasil.

<profaclaudiamartiniano@gmail.com>

${ }^{3}$ Universidade Estadual da Paraíba, Departamento de Enfermagem, Campina Grande, Paraíba, Brasil.

<ardigleusacoelho@gmail.com> 
${ }^{4}$ Escola de Saúde da Universidade Federal do Rio Grande do Norte, Programa de PósGraduação em Práticas de Saúde e Educação. Natal, Rio Grande do Norte, Brasil.

$<$ marizebs@gmail.com>

${ }^{5}$ Universidade Federal do Rio Grande do Norte, Departamento de Saúde Coletiva, Natal, Rio Grande do Norte, Brasil.

$<$ themisbr@hotmail.com>

${ }^{6}$ Universidade Federal do Rio Grande do Norte, Departamento de Saúde Coletiva, Natal, Rio Grande do Norte, Brasil.

<paulodemedeirosrocha@gmail.com>

\section{Referências}

BELLINI, Marcella; PIO, Danielle A. M.; CHIRELLI, Mara Q. O apoiador institucional da Atenção Básica: a experiência em um município do interior paulista. Saúde em Debate. Rio de Janeiro, v. 40, n. 108, p. 23-33, jan.-mar. 2016.

BERTUSSI, Débora C. O apoio matricial rizomático e a produção de coletivos na gestão municipal em saúde. 2010. $234 \mathrm{f}$. Tese (Doutorado em Clínica Médica) - Universidade Federal do Rio de Janeiro, Rio de Janeiro, 2010.

BRASIL. Ministério da Saúde. Secretaria Executiva. Núcleo Técnico da Política Nacional de Humanização. HumanizaSUS. Brasília: Ministério da Saúde, 2003.

Disponível em: <http://bvsms.saude.gov.br/ bvs/publicacoes/humanizaSus.pdf $>$. Acesso em: 20 jan. 2016.

BRASIL. Ministério da Saúde. Secretaria Executiva. Departamento de Apoio à Descentralização. Apoio integrado à gestão descentralizada do SUS: estratégia para a qualificação da gestão descentralizada. Ministério da Saúde - Brasília: Ministério da Saúde, 2004. Disponível em: <http:// bvsms.saude.gov.br/bvs/publicacoes/cd09_18. pdf $>$. Acesso em: 15 out. 2014.

BRASIL. Ministério da Saúde. Secretaria de Atenção à Saúde. Núcleo Técnico da Política Nacional de Humanização. Ambiência. 2. ed. Brasília: Ministério da Saúde, 2010.
BRASIL. Ministério da Saúde. Portaria n. 1.654, de 19 de julho de 2011. Institui, no âmbito do Sistema Único de Saúde, o Programa Nacional de Melhoria do Acesso e da Qualidade da Atenção Básica (PMAQ-AB) e o Incentivo Financeiro do PMAQ-AB, denominado Componente de Qualidade do Piso de Atenção Básica Variável - PAB Variável. Diário Oficial da República Federativa do Brasil, Poder Executivo, Brasília, DF, 20 jul. 2011d. Disponível em: <http://bvsms.saude.gov. br/bvs/saudelegis/gm/2011/prt1654_19_07_2011. html>. Acesso em: 10 out. 2013.

BRASIL. Ministério da Saúde. Secretaria de Atenção à Saúde. Departamento de Atenção Básica. Programa Nacional de Melhoria do Acesso e da Qualidade da Atenção Básica (PMAQ): manual instrutivo para as equipes de Atenção Básica e NASF. $3^{\circ}$ Ciclo (2015-2016). Brasília: Ministério da Saúde, 2015. Disponível em: $<$ http://189.28.128.100/dab/docs/portaldab/ documentos/Manual_Instrutivo_3_Ciclo_PMAQ. pdf $>$. Acesso em: 20 dez. 2016.

BRASIL. Ministério da Saúde. Secretaria de Atenção à Saúde. Departamento de Atenção Básica. Autoavaliação para a melhoria do acesso e da qualidade da atenção básica: AMAQ. Brasília: Ministério da Saúde, 2012. No prelo. Disponível em: <http://189.28.128.100/dab/docs/sistemas/ Pmaq/amaq_2011.pdf $>$. Acesso em: 5 jul. 2014.

CAMPOS, Gastão W. S. Um método para análise e cogestão de coletivos. 3. ed. São Paulo: Hucitec, 2000. 
CAMPOS, Gastão W. S. Saúde Paideia. São Paulo: Hucitec, 2003.

CAMPOS, Gastão W. S. Clínica e saúde coletiva compartilhadas: teoria paideia e reformulação ampliada do trabalho em saúde. In: CAMPOS, Gastão Wagner et al. (orgs.). Tratado de saúde coletiva. 2. ed. São Paulo: Hucitec, 2008. v. 1, p. 53-93.

CAMPOS, Gastão W. S. Apoio matricial e institucional em saúde. Entrevista: Gastão Wagner de Sousa Campos. Entrevistador: Liane Beatriz Righi. Interface: Comunicação, Saúde e Educação, Botucatu, v. 18, supl. 1, p. 11451150, dez. 2014. Disponível em: <http://www. scielo.br/scielo.php?script $=$ sci_arttext\&pi$\mathrm{d}=$ S1414=32832014000501145-\&lng=en\&nrmiso >. Acesso em: 28 maio 2015.

CAMPOS, Gastão W. S.; CUNHA, Gustavo T.; FIGUEIREDO, Mariana D. Práxis e formação Paideia: apoio e cogestão em saúde. São Paulo: Hucitec, 2013.

CARDOSO, Janaina R; OLIVEIRA, Gustavo N.; FURLAN, Paula G. Gestão democrática e práticas de apoio institucional na Atenção Primária à Saúde no Distrito Federal, Brasil. Cadernos de Saúde Pública, Rio de Janeiro, v. 32, n. 3, p.1-13, mar. 2016.

COSTA, Renata. M. O. O processo de trabalho da equipe de apoio institucional com foco na gestão do trabalho e da educação na Atenção Básica no Estado da Bahia. 2009. 122 f. Dissertação (Mestrado Profissional em Saúde Pública) Escola Nacional de Saúde Pública Sergio Arouca, Fundação Oswaldo Cruz, Rio de Janeiro, 2009. Disponível em: <http://www.arca. fiocruz. br/bitstream/icict/2293/1/ENSP_Disserta\% C3\% A $7 \%$ C $3 \%$

A3o_Costa_Renata_Maria_Oliveira.pdf $>$. Acesso em: 15 nov. 2014.

CRUZ, Marly M. da et al. Usos do planejamento e autoavaliação nos processos de trabalho das equipes de saúde da família na atenção básica. Saúde em Debate, Rio de Janeiro, v. 38, n. esp., p. 124-139, out. 2014.
FALLEIRO, Letícia M. et al. Considerações preliminares sobre apoio institucional e educação permanente. In: FALLEIRO, Letícia M. (org.). Experiências de apoio institucional no SUS: da teoria à prática. Porto Alegre: Rede Unida, 2014. p. 19-30.

FERNANDES, Juliana A.; FIGUEIREDO, Mariana D. Apoio institucional e cogestão: uma reflexão sobre o trabalho dos apoiadores do SUS Campinas. Physis: Revista de Saúde Coletiva, Rio de Janeiro, v. 25, n. 1, p. 287-306, 2014.

GARNELO, Luiza et al. Avaliação externa do PMAQ no Amazonas: experiências e narrativas sobre a implementação da política nacional de atenção básica. In: FAUSTO, Márcia C. R.; FONSECA, Helena M. S. (orgs.). Rotas da atenção básica no Brasil: experiências do trabalho de campo PMAQ-AB. Rio de Janeiro: Saberes, 2013. p. 58-87.

GIOVANELLA, Ligia; ESCOREL, Sarah M.; MENDONÇA, Maria H. M. Estudos de caso sobre implementação da estratégia saúde da família em quatro grandes centros urbanos. Relatório final. Belo Horizonte: Escola Nacional de Saúde Pública Sérgio Arouca; Fundação Oswaldo Cruz, 2009. Disponível em: <http:// www5.ensp.fiocruz.br/biblioteca/dados/ txt_87826732.pdf>. Acesso em: 30 mar. 2014.

GRANDO, Maristel K.; DALL'AGNOL, Clarice $M$. Desafios do processo grupal em reuniões de equipe da estratégia saúde da família. Escola Anna Nery, Rio de Janeiro, v. 14, n. 3, p. 504-510, set. 2010. Disponível em: <http:// www.scielo.br/scielo.php?script=sci_arttext\&pi$\mathrm{d}=$ S1414=81452010000300011-\&lng=en\&nrmiso >. Acesso em: 1 mar. 2015.

GUEDES, Carla R.; ROZA, Mônica M. R.; BARROS, Maria E. B. de. O apoio institucional na política nacional de humanização: uma experiência de transformação das práticas de produção de saúde na rede de atenção básica. Cadernos de Saúde Coletiva, Rio de Janeiro, v. 20, n. 1, p. 93-101, 2012. Disponível em: <http://www.cadernos.iesc.ufrj.br/cadernos/ images/csc/2012_1/artigos/CSC_v20n1_93-101. pdf $>$. Acesso em: 20 mar. 2014. 
KAWATA, Lauren S. et al. O trabalho cotidiano da enfermeira na saúde da família: utilização de ferramentas da gestão. Texto \& Contexto Enfermagem, Florianópolis, v. 18, n. 2, p. 313-320, 2009. Disponível em: <http:// www.scielo.br/pdf/tce/v18n2/15.pdf $>$. Acesso em: 12 mar. 2015.

MISHIMA, Silvana M. A gerência de serviços de atenção primária à saúde como instrumento para a reorganização da assistência à saúde: o caso do programa de saúde da família. 2003. 153p. Tese (Doutorado em Livre-Docência) - Escola de Enfermagem de Ribeirão Preto, Universidade de São Paulo, Ribeirão Preto, 2003.

OLIVEIRA, Gustavo N. O projeto terapêutico singular. In: BRASIL. Ministério da Saúde. Secretaria de Atenção à Saúde. Política Nacional de Humanização: Atenção Básica. Brasília: Ministério da Saúde, 2010. p. 93-104. (Cadernos HumanizaSUS, 2)

OLIVEIRA, Gustavo O. O apoio institucional aos processos de democratização das relações de trabalho na perspectiva da humanização. Revista Tempus: Actas de Saúde Coletiva, Brasília, v. 6, n. 2, 2012. Disponível em: $<$ http://www.tempusactas.unb.br/index. $\mathrm{php} /$ tempus/article/view/1125>. Acesso em: 16 maio 2013.

PAIXÃO, Lara; TAVARES, Maria F. L. A construção do projeto 'Apoio de Rede' como estratégia institucional. Interface: Comunicação, Saúde e Educação, Botucatu, v. 18, supl. 1, p. $845-858,2014$. Disponível em: <http:// dx.doi.org/10.1590/1807-57622013.0203>. Acesso em 20 nov. 2014.

PAULON, Simone M.; PASCHE, Dário F.; RIGHI, Liane B. Função apoio: da mudança institucional à institucionalização da mudança. Interface: Comunicação, Saúde e Educação, Botucatu, v. 18, supl. 1, p. 809-820, dez. 2014. Disponível em: <http://www. scielo.br/scielo.php?script=sci_arttext \&pi$\mathrm{d}=$ S1414=32832014000500809-\&lng=en\&nrmiso >. Acesso em: 17 maio 2015.
PAVAN, Cleusa; TRAJANO, Ana R. C. Apoio institucional e a experiência da Política Nacional de Humanização (PNH) na Freguesia do Ó, Brasilândia, São Paulo, Brasil. Interface: Comunicação, Saúde e Educação, Botucatu, v.18, supl.1, p. 1027-1040, 2014. Disponível em: <http://dx.doi.org/10.1590/180757622013.0229>. Acesso em 15 dez. 2014.

PEREIRA JÚNIOR, Nilton; CAMPOS, Gastão W. S. O apoio institucional no Sistema Único de Saúde (SUS): os dilemas da integração interfederativa e da cogestão. Interface: Comunicação, Saúde e Educação, Botucatu, v. 18, supl. 1, p. 895-908, dez. 2014. Disponível em < http:// www.scielo.br/scielo.php?script=sci_arttext\&pi$\mathrm{d}=$ S1414=32832014000500895-\&lng=pt\&nrmiso >. Acesso em: 17 maio 2015.

SARTI, Thiago D. et al. A institucionalização da avaliação na atenção básica: alguns aspectos para a construção de práticas democráticas no contexto da estratégia saúde da família: UFES. Revista Odontologia, v. 10, n. 1, p. 63-69, 2008. Disponível em: <http://periodicos.ufes. br/RBPS/article/viewFile/492/356> . Acesso em: 7 fev. 2013.

SARTI, Thiago D. et al. Avaliação das ações de planejamento em saúde empreendidas por equipes de saúde da família. Cadernos de Saúde Pública, Rio de Janeiro, v. 28, n. 3, mar. 2012. Disponível em: <http://www. scielo.br/scielo.php?script=sci_arttext\&pi$\mathrm{d}=$ S0102=311-2012000300014X\&lng =en \&nrmiso >. Acesso em: 12 mar. 2015.

SANTOS, Alaneir F. et al. Apoio institucional e matricial e sua relação com o cuidado na atenção básica à saúde. Revista de Saúde Pública. São Paulo, v. 49, 54, ago. 2015.

SENNA, Mônica C. M.; COSTA, Andréia M.; SILVA, Luana N. Atenção à saúde em grandes centros urbanos: desafios à consolidação do SUS. Sociedade em Debate, Pelotas, v. 16, n. 1, p. 121-137, jan.-jun. 2010. Disponível em: $<$ http://revistas.ucpel.tche.br/index.php/ rsd/article/view/341/299>. Acesso em: 21 maio 2015. 
SIMÕES, Arlete L. Trabalho e saúde de equipes da Saúde da Família em contextos socioambientais vulneráveis no municipio de Manaus. 2014. 104 f. Tese (Doutorado em Saúde Pública) - Escola Nacional de Saúde Pública Sergio Arouca, Fundação Oswaldo Cruz, Rio de Janeiro, 2014. Disponível em: <http://bvssp.icict.fiocruz.br/ lildbi/docsonline/get.php?id=3942>. Acesso em: 3 mar. 2015.

Recebido em 10/04/2016

Aprovado em 02/07/2016 
